Journal of the Operations Research

Society of Japan

Vol. 23, No. 2, June 1980

\title{
A GROUP THEORETIC DUAL PROBLEM WITHOUT DUALITY GAPS FOR
} BOUNDED INTEGER PROGRAMS

\author{
Yoshitsugu Yamamoto \\ Tokyo Institute of Technology \\ (Received July 7, 1979)
}

\begin{abstract}
We present a procedure for constructing a group theoretic dual problem with no duality gap to a given bounded integer programming problem. An optimal solution of this dual problem is easily determined and an optimal. solution of the integer programming problem can be obtained by solving only one group optimization problem.
\end{abstract}

\section{Introduction}

Since Held and Karp [11,12] reported a very promising result about their algorithm for the travelling salesman problem, their approach, which is now interpreted as a dual method, has been extended to general integer programmings (see [8]). Especially Fisher and Shapiro [5] combined the dual method with the relaxation of linear constraints into a group congruence (see also [6]). They showed that their dual problem provides a better bound than the ordinary linear programming relaxation. However it can be seen that there generally exist duality gaps. Bel1 [1,2], and Bell and Shapiro [3] have proved that duality gaps can be closed up by introducing increasingly stronger group congruence conditions in finite Abelian groups.

In the subsequent sections of this paper we shall propose a procedure to construct a dual problem for bounded integer programmings, and show that duality gaps are eliminated and an optimal solution is easily obtained in this dual problem. 
1. Lagrangean dual problem

We consider the following integer programming problem:

$$
z^{*}=\operatorname{minimize} \mathrm{cx} \text {, }
$$$$
\text { subject to } \mathrm{x} \varepsilon \mathrm{X}=\left\{\mathrm{x} \mid \mathrm{Ax} \leqq \mathrm{b}, 0 \leqq \mathrm{x} \leqq M, x \in \mathrm{Z}^{\mathrm{n}}\right\} \text {, }
$$

where $A=\left(a_{i j}\right) \varepsilon z^{m \times n}, b=\left(b_{1}, b_{2}, \ldots, b_{m}\right)^{t} \varepsilon z^{m}, M=\left(M_{1}, M_{2}, \ldots, M_{n}\right)^{t} \varepsilon z^{n}$ and $c=\left(c_{1}, c_{2}, \ldots, c_{n}\right) \varepsilon R^{n}$. Without loss of generality we assume that the region $\{\mathrm{x} \mid \mathrm{Ax} \leqq \mathrm{b}, 0 \leqq \mathrm{x}\}$ is bounded (e.g., add $\Sigma_{j=1}^{\mathrm{n}} \mathrm{x}_{j} \leqq \Sigma_{j=1}^{\mathrm{n}} \mathrm{M}_{j}$ ). By relaxing the inequality constraints $A x \leqq b$ in $x$, we define the set

$$
\overline{\mathrm{x}}=\left\{\mathrm{x} \mid 0 \leqq \mathrm{x} \leqq M, x \in \mathrm{z}^{\mathrm{n}}\right\},
$$

which we shall also write as $\bar{X}=\left\{x^{s} \mid s \in s\right\}$. Putting nonnegative multipliers $\mathrm{u}=\left(\mathrm{u}_{1}, \mathrm{u}_{2}, \ldots, \mathrm{u}_{\mathrm{m}}\right)$ on the constraints $\mathrm{Ax} \leqq \mathrm{b}$, we define

$$
L(u, s)=-u b+(c+u A) x^{s}
$$

and cal1

$$
L(u)=\min \{L(u, s) \mid s \varepsilon s\}
$$

the Lagrangean function for the problem (1-1). It is known and easily shown that $\mathrm{L}(\mathrm{u}) \leqq z^{*}$ for any nonnegative multiplier vector $\mathrm{u}$. Thus the problem to find the best of these lower bounds is formulated as

$$
\begin{aligned}
L^{*}= & \operatorname{maximize} L(u), \\
& \text { subject to } u \geq 0 .
\end{aligned}
$$

This problem, a maximization problem of the piecewise linear concave function $\mathrm{L}(\mathrm{u})$, is called the Lagrangean dual problem of (1-1) [8]. Although several algorithms have been proposed for this problem $[5,6,10]$, the optimal multiplier vector is not easy to obtain and there is no guarantee that $L^{*}=z^{*}$, i.e., duality gaps generally exist.

For a positive integer vector $d=\left(d_{1}, d_{2}, \ldots, d_{m}\right)^{t}$ define the sets

$$
\begin{aligned}
& \mathrm{Y}_{\mathrm{d}}=\left\{(\mathrm{x}, \mathrm{y}) \mid \begin{array}{l}
\mathrm{y}+\mathrm{Ax} \leq \mathrm{b}, \mathrm{y}+\mathrm{Ax} \equiv \mathrm{b} \quad(\bmod \mathrm{d}), \\
0 \leqq \mathrm{x} \leq \mathrm{M}, 0 \leqq \mathrm{y}<\mathrm{d}, \mathrm{x} \varepsilon \mathrm{z}^{\mathrm{n}}, \mathrm{y} \varepsilon \mathrm{z}^{\mathrm{m}}
\end{array}\right\}, \\
& \mathrm{x}_{\mathrm{d}}=\left\{\mathrm{x} \mid(\mathrm{x}, \mathrm{y}) \varepsilon \mathrm{Y}_{\mathrm{d}} \text { for some } \mathrm{y}\right\},
\end{aligned}
$$

then we obtain Lemma 1 , where $a \equiv b(\bmod d)$ means that $a_{i} \equiv b_{i}\left(\bmod d_{i}\right)$ for $i=1,2, \ldots, m$. Though the proof of the following lemma can be found in [1], we shall give the proof for consistency. 
Lemma 1.

$\mathrm{X}=\mathrm{X}_{\mathrm{d}}$ for any positive integer vector $\mathrm{d}$.

proof. It is sufficient to show that $\mathrm{x} \subset \mathrm{x}_{\mathrm{d}}$. For an arbitrary vector $\mathrm{x}$ in $\mathrm{x}, \overline{\bar{y}}=\mathrm{b}-\mathrm{Ax}$ is a nonnegative integer vector. Then there uniquely exists a pair of vectors $\bar{y}$ and $y$ such that $\bar{y}=\Delta \bar{y}+y, 0 \leqq \bar{y}, 0 \leqq y<d$, where

$$
\Delta=\left(\begin{array}{ccc}
{ }^{d_{1}} & & 0 \\
& & \\
0 & & d_{m}
\end{array}\right) .
$$

Hence $\mathrm{b}-(\mathrm{y}+\mathrm{Ax})=\Delta \overline{\mathrm{y}} \geqq 0$ and $\equiv 0(\bmod \mathrm{d})$, i.e., $\mathrm{x}$ i.s in $\mathrm{x}_{\mathrm{d}}$.

Relaxing again the inequality conditions in $\mathrm{Y}_{d}$ and $\mathrm{X}_{\mathrm{d}}$ defines

$$
\begin{aligned}
& \overline{\mathrm{Y}}_{\mathrm{d}}=\left\{(\mathrm{x}, \mathrm{y}) \mid \begin{array}{ll}
\mathrm{y}+\mathrm{Ax} \equiv \mathrm{b} \quad(\bmod \mathrm{d}), \\
0 \leqq \mathrm{x} \leqq \mathrm{M}, 0 \leqq \mathrm{y}<\mathrm{d}, \mathrm{x} \varepsilon \mathrm{z}^{\mathrm{n}}, \mathrm{y} \varepsilon \mathrm{z}^{\mathrm{m}}
\end{array}\right\}, \\
& \overline{\mathrm{X}}_{\mathrm{d}}=\left\{\mathrm{x} \mid(\mathrm{x}, \mathrm{y}) \varepsilon \overline{\mathrm{Y}}_{\mathrm{d}} \text { for some } \mathrm{y}\right\} .
\end{aligned}
$$

It is seen that $\bar{X}=\bar{X}_{d}$ for any positive integer vector $d$ in the same way as in the proof of Lemma 1 and for any $x \in \bar{X}_{d}$ the vector $y$ such that $(x, y) \varepsilon \bar{Y}_{d}$ is uniquely determined. Hence we also denote $\bar{Y}_{d}=\left\{\left(x^{s}, y^{s}\right) \mid s \in S\right\}$. Therefore the problem (1-1) may be written equivalent1y as

$$
\begin{aligned}
z^{*}= & \text { minimize } \mathrm{cx}^{\mathrm{s}}, \\
& \text { subject to } \mathrm{y}^{\mathrm{S}}+\mathrm{Ax}^{\mathrm{s}} \leqq \mathrm{b}, \mathrm{s} \varepsilon \mathrm{s} .
\end{aligned}
$$

For any nonnegative multiplier vector $u$, define

$$
\begin{aligned}
& L_{d}(u, s)=-u b+(c+u A) x^{s}+u y^{s}, \\
& L_{d}(u)=\min \left\{L_{d}(u, s) \mid s \varepsilon s\right\}
\end{aligned}
$$

then the problem (1-3) is dualized as

$$
\begin{aligned}
L_{d}^{*}= & \operatorname{maximize} L_{d}(u), \\
& \text { subject to } u \geq 0 .
\end{aligned}
$$

It should be noted that if $d=(1,1, \ldots, 1)^{t}$ then $L_{d}(u, s)=L(u, s)$ for any $s \varepsilon s$.

In the next section we shall show that there exists a finitely large $d$ for which an optimal multiplier vector $u^{*}$ is easily determined and it is sufficient to solve only one group optimization problem to obtain an optimal solution of the problem (1-1). 
2. Resolution of the duality gap

Let $D=\left(D_{1}, D_{2}, \ldots, D_{m}\right)^{t}$ be defined such that for $i=1,2, \ldots, m$

$$
D_{i}=\max \left\{b_{i}-A_{i} x^{s} \mid s \in s\right\} \text {, }
$$

where $A_{i}$ is the $i$-th row of the constraint matrix $A$. Note that $D_{i} \geqslant 0$ if $(1-1)$ has a feasible solution.

\section{Lemma 2.}

Let $d>D$ be a positive integer vector. Then for any $\left(x^{S}, y^{s}\right) \varepsilon \bar{Y}_{d}$, (i) $\quad y_{i}^{s}+A_{i} x^{s}-b_{i}=0$ if $A_{i} x^{s} \leqq b_{i}$, (ii) $y_{i}^{s}+A_{i} x^{s}-b_{i} \geqq d_{i} \quad$ otherwise.

proof. (i) Suppose that $A_{i} x^{s} \leqq b_{i}$, then by $(2-1)$ and $0 \leqq y_{i}<d_{i}$

$$
-d_{i}<y_{i}^{s}+A_{i} x^{s}-b_{i}<d_{i} \text {. }
$$

Hence it follows from $y_{i}^{s}+A_{i} x^{s}-b_{i} \equiv 0\left(\bmod d_{i}\right)$ that $y_{i}^{s}+A_{i} x^{s}-b_{i}=0$. (ii) For $x^{s}$ such that $A_{i} x^{s}>b_{i}, 0<y_{i}^{s}+A_{i} x^{s}-b_{i} \equiv 0\left(\bmod d_{i}\right)$. Then for some positive integer $k, y_{i}+A_{i} x^{s}-b_{i}=k \cdot d_{i}$ which is not less than $d_{i}$.

Lemma 2 reveals that if $x^{s}$ is feasible in (1-1) then the value of $L_{d}(u, s)$ is independent of the amount of $u$, while if $x^{s}$ is infeasible, i.e., $A_{i} x^{s}>b_{i}$ for some $i$, then $L_{d}(u, s)$ ascends in the $i$-th coordinate direction (see Fig.1). Define

$$
\underline{z}=\min \left\{\mathrm{cx}^{\mathrm{s}} \mid \mathrm{s} \in \mathrm{s}\right\},
$$

and $\bar{z}$ as an upper bound on $z^{*}$.

Theorem 3.

Let $U_{i}=(\bar{z}-\underline{z}) / d_{i}$ for an arbitrarily fixed $d>D$. If $(1-1)$ has a feasible solution, then $(i)$ and (ii) hold for any $u *>U=\left(U_{1}, U_{2}, \ldots, U_{m}\right)$.

(ii) $x^{s}$ is an optimal solution of (1-1) for any $s \in s_{d}\left(u^{*}\right)=\{s \mid s \in s$, $\left.L_{d}(u *)=L_{d}(u *, s)\right\}$.

proof. For an infeasible solution $x^{\mathbf{S}}$ of $(1-1)$, define the nonempty set

$$
I=\left\{i \mid A_{i} x^{s}>b_{i}\right\},
$$

then by Lemma 2 , we have 


$$
\begin{array}{rlrl}
L_{d}\left(u^{*}, s\right) & =c x^{s}+u^{*}\left(y^{s}+A x^{s}-b\right) & \\
& =c x^{s}+\Sigma_{i \varepsilon I} u_{i}^{*}\left(y_{i}^{s}+A_{i} x^{s}-b_{i}\right) \\
& \geqslant c x^{s}+\sum_{i \varepsilon I} u_{i}^{*} \cdot d_{i} & \left.\quad \text { (by Lemma } 2 \text { and } u^{*}>0\right) \\
& >c x^{s}+\sum_{i \varepsilon I}(\bar{z}-\underline{z}) & \left.\quad \text { (by the choice of } u^{*}\right) \\
& \geqslant \bar{z}+\left(c x^{s}-\underline{z}\right) & \\
& \geqq \bar{z} & & \text { (by the definition of } \underline{z})
\end{array}
$$

Let $s^{*}$ be any index in $S_{d}\left(u^{*}\right)$. Since $y^{s}+A x^{s}-b=0$ for any feasible solution $x^{S}$ of (1-1), we have

$$
L_{d}\left(u^{*}, s^{*}\right) \leqq L_{d}\left(u^{*}, s\right)=c x^{S}
$$

for any feasible solution $x^{s}$ of $(1-1)$, which implies that

$$
\mathrm{L}_{\mathrm{d}}\left(\mathrm{u} *, \mathrm{~s}^{*}\right) \leqq \bar{z} \text {. }
$$

Then by (2-2) and (2-4) we have that $\mathrm{x}^{\mathrm{s}^{*}}$ is feasible in (1-1), thus

$$
\mathrm{L}_{\mathrm{d}}\left(\mathrm{u}^{*}, \mathrm{~s}^{*}\right)=\mathrm{cx}^{\mathrm{s}} \text {. }
$$

Comparing (2-3) and (2-5) gives the desired result (ii).

(i) follows directly from the weak duality $L_{d}^{*} \leqq z^{*}$ and $z^{*}=c x^{S^{*}}=L_{d}\left(u^{* *}\right)$.

Note that if $\mathrm{x}^{\mathrm{s}^{*}}$ is infeasible in (1-1), then (1-1) has no feasible solution. Also note that $\underline{z}=\Sigma_{j \varepsilon J} c_{j} M_{j}$ and $D_{i}=b_{i}-\Sigma_{j \varepsilon J} a_{i j} M_{j}, i=1,2, \ldots$,

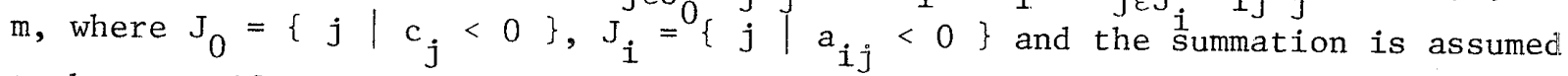
to be zero if $\mathrm{J}_{i}$ is empty.

It follows from Theorem 3 that an optimal solution of (1-1) is obtained by solving the group optimization problem with the additional bounded-variable constraints:

$$
\begin{aligned}
& \operatorname{minimize}-\mathrm{u}^{*} \mathrm{~b}+(\mathrm{c}+\mathrm{u} * \mathrm{~A}) \mathrm{x}+\mathrm{u}^{*} \mathrm{y}, \\
& \text { subject to } \mathrm{y}+\mathrm{Ax} \equiv \mathrm{b}(\bmod \mathrm{d}), \\
& 0 \leqq \mathrm{x} \leqq \mathrm{M}, 0 \leqq \mathrm{y}<\mathrm{d}, \mathrm{x} \varepsilon \mathrm{z}^{\mathrm{n}}, \mathrm{y} \varepsilon \mathrm{z}^{\mathrm{m}},
\end{aligned}
$$

where the upper bound constraints on $y$ might be deleted since $u *>0$ and $y_{i}-d_{i}$ $\equiv y_{i}\left(\bmod d_{i}\right)$.

For group optimization problems several algorithms have been proposed [4, $7,10]$, and some of those are applicable to the bounded-variable case [9]. A1though most of the algorithms for group optimazation problems require the nonnegativity of the objective function coefficients, it is not necessary in (2-6) since the bounded-variable constraints serve to make the number of possible 
solutions finite. It is preferable, however, to make the objective function coefficients nonnegative from the computational point of view.

Lemma 4.

If the bounded region $\{\mathrm{x} \mid \mathrm{Ax} \leqq \mathrm{b}, 0 \leqq \mathrm{x}\}$ is nonempty, then there exists a multiplier vector $\mathrm{u}^{*}$ satisfying both $\mathrm{c}+\mathrm{u}^{*} \mathrm{~A} \geqq 0$ and $\mathrm{u}^{*} \geqq \mathrm{~V}$ for a given $\mathrm{V}$.

proof. Suppose on the contrary no such $u^{*}$ exists, then by Gale's alternative theorem there exist nonnegative vectors $z$ and $y$ such that $A z+y=0$ and $c z-V y$ $=-1$. Then $z \neq 0$ for otherwise $c z-V y=0$, which is a contradiction. Therefore we obtain that $z \geq 0$ and $A z=-y \leq 0$ which contradicts to the assumption that the region is bounded and nonempty.

It is known that the problem $(2-6)$ can be considered as a shortest path problem on a network having $\prod_{i=1}^{m} d_{i}$ number of nodes. The edges of the network are classified into $n+1$ groups and it is required that the number of edges of the same group contained in the path must not exceed the bounded constant value. Hence it is desired from the computational point of view in solving (2-6) that each component $d_{i}$ is as small as possible. But if $d_{i}$ is smaller than the value presented in Lemma 2, we must solve a maximization problem (1-4) of the piecewise linear concave function $\mathrm{L}_{\mathrm{d}}(\mathrm{u})$ to find an optimal multiplier vector. Furthermore there is no guarantee that the duality gap is closed up. Thus further investigation and computational experiments are required in order to find the way of deciding "optimal" value of $d$.

3. Illustrative example

Consider the following knapsack problem:

$$
\begin{aligned}
& \text { minimize }-\left(12 x_{1}+7 x_{2}+6 x_{3}\right) \text {, } \\
& \text { subject to } 3 x_{1}+2 x_{2}+2 x_{3} \leqq 4 \text {, } \\
& x_{j} \text { is } 0 \text { or } 1 \text { for } j=1,2,3
\end{aligned}
$$

with an optimal solution $x=(0,1,1)$ and the optimal value -13 . By the definition we have $\mathrm{d}=5$ and $\underline{z}=-25$. since $\mathrm{x}=(0,0,0)$ is a trivial feasible solution, $\bar{z}=0$ is an upper bound on $z^{*}$. Then $U=25 / 5=5$ and $u^{*}=6$ is sufficient to make the objective function coefficients nonnegative. The group optimization problem is as follows: 


$$
\begin{array}{ll}
\text { minimize }-24+ & 6 x_{1}+5 x_{2}+6 x_{3}+6 y, \\
\text { subject to } & 3 x_{1}+2 x_{2}+2 x_{3}+y \equiv 4 \text { (nod 5), } \\
& x_{j} \text { is } 0 \text { or } 1 \text { for } j=1,2,3, \\
& 0 \leqq y \text { integer. }
\end{array}
$$

To illustrate how $\mathrm{d}$ and $\mathrm{u}^{*}$ work, $\mathrm{L}_{\mathrm{d}}(\mathrm{u}, \mathrm{s})$ are depicted for all possible solutions $\mathrm{x}^{\mathrm{s}}$ and for $\mathrm{d}=1,3,5$ in Fig. 2. where darkened 1ines represent $L_{d}(u)$.

\section{Acknowledgment}

Most of this work was done while the author was in the Department of Administration Engineering, Keio University. He wishes to thank T.Murakami for valuable discussions and careful reading of the manuscript.

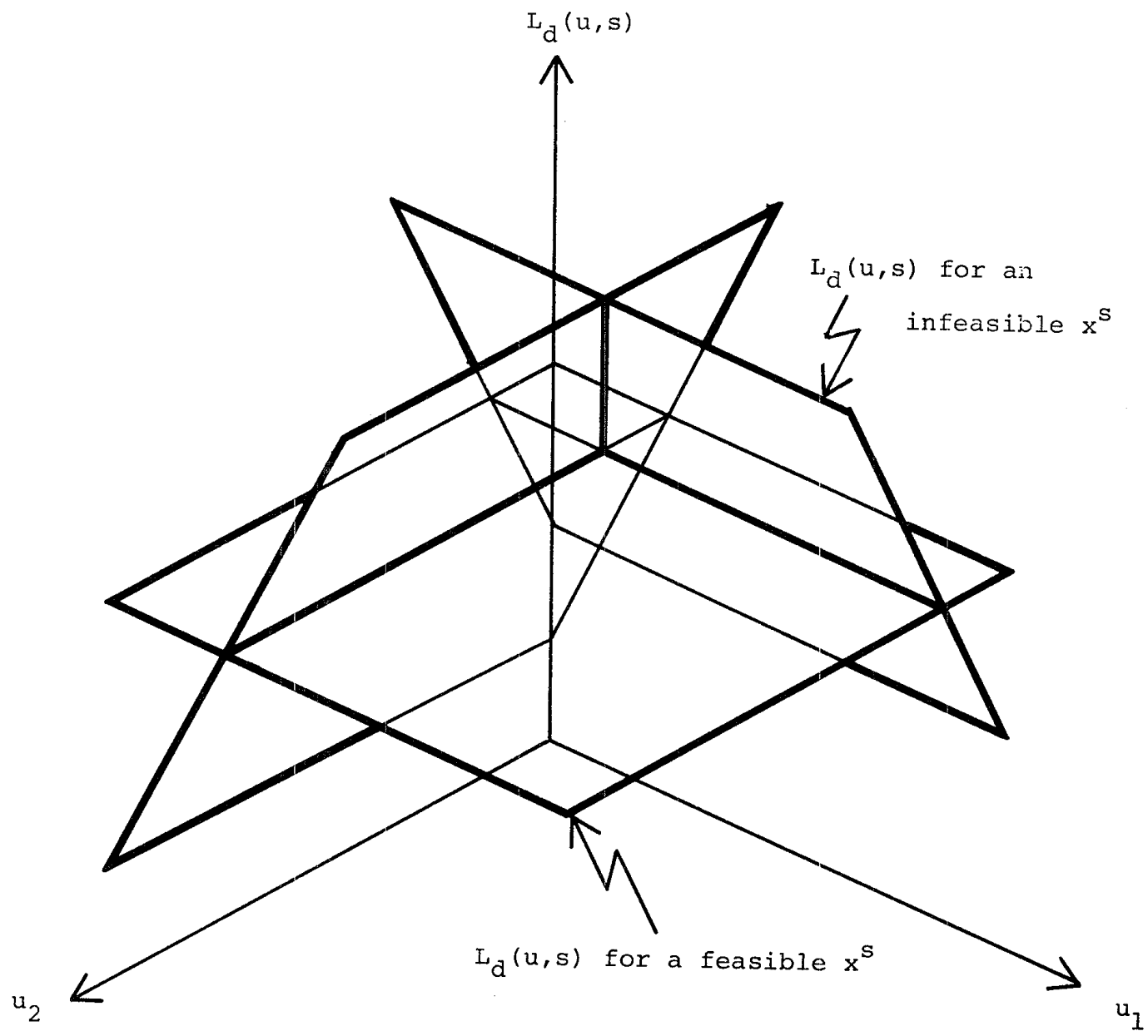

Fig. I 


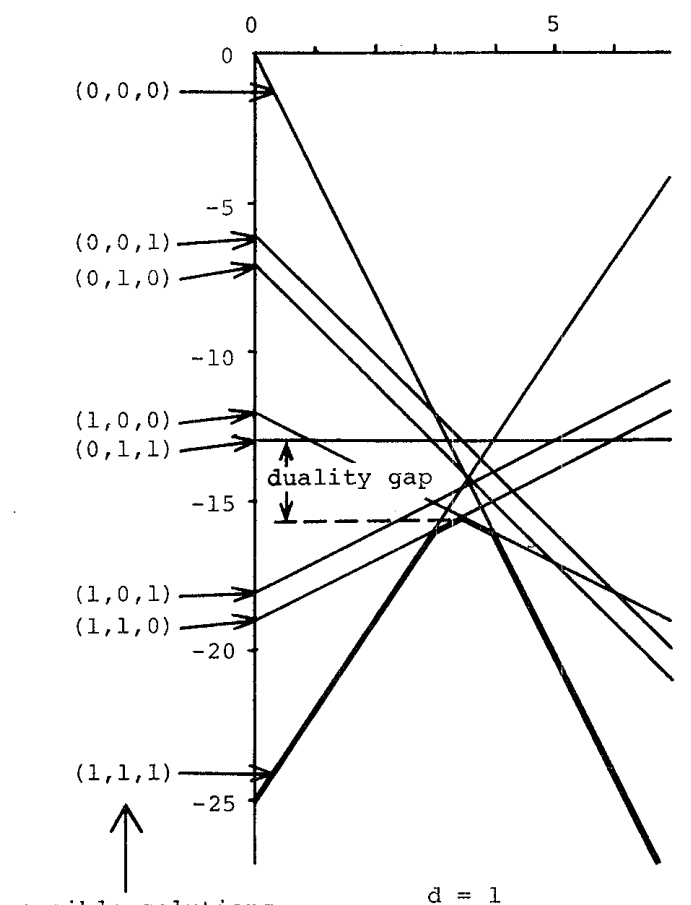

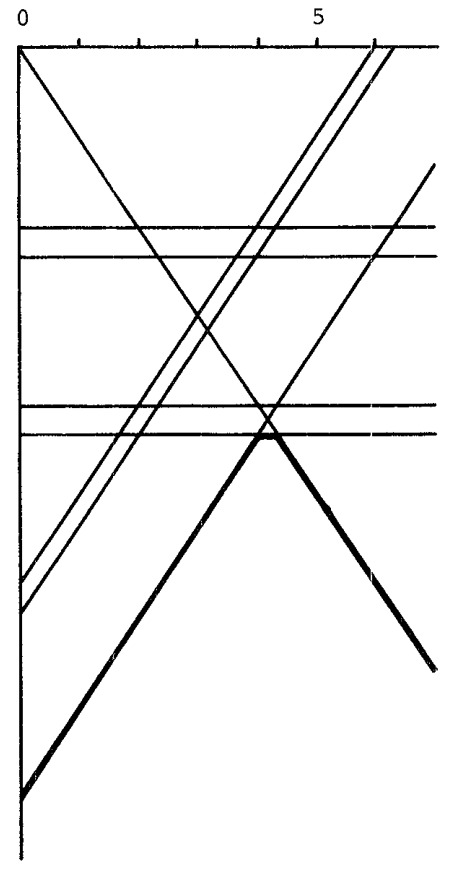

$d=3$

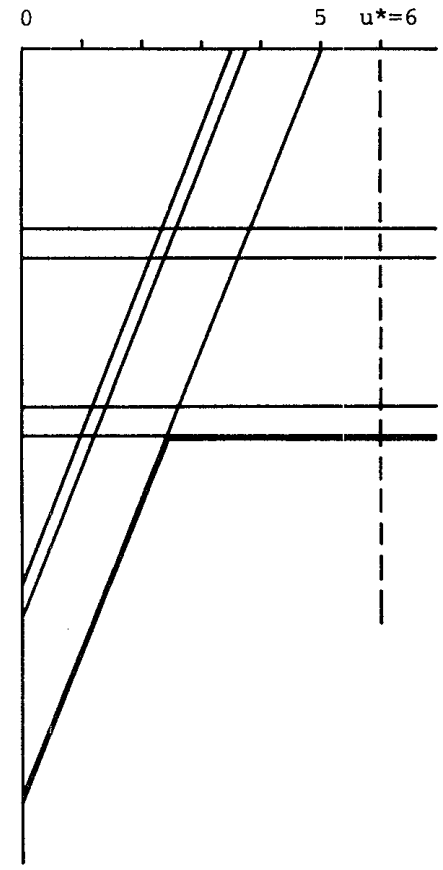

$d=5$

Fig. 2

\section{References}

[1] Bell,D.E.,"Constructive Group Relaxation for Integer Programs", SIAM J. App 2. Math., 30 (1976) 708-719.

[2] Bell,D.E.,"A Simple Algorithm for Integer Programs Using Group Constraints", Operational Research Quarterly, 28 (1977) 453-458.

[3] Be11,D.E. and Shapiro,J.F.,"A Convergent Duality Theory for Integer Programming", Operations Research, 25 (1977) 419-434.

[4] Chen,D. and Zionts, S.,"Comparison of Some Algorithms for Solving the Group Theoretic Integer Programming Problem", Operations Research, 24 (1976) 1120-1128.

[5] Fisher,M.L. and Shapiro,J.F.,"Constructive Duality in Integer Programming", SIAM J. Appl. Math., 27 (1974) 31-52.

[6] Fisher,M.L., Northup,W.D. and Shapiro,J.F.,"Using Duality to Solve Discrete Optimization Problems", Math. Prog. Study, 3 (1975) 56-94.

[7] Frieze,A.M.,"Shortest Path Algorithm for Knapsack Type Problems", Math. Prog., 11 (1976) 150-157.

[8] Geoffrion,A.M., "Lagrangean Relaxation for Integer Programming", Math. Prog. Study, 2 (1974) 82-114. 
[9] Gorry,G.A. and Shapiro,J.F., "An Adaptive Group Theoretic Algorithm for Integer Programming Problems", Management Sci., 17 (1971) 285-306.

[10] Gorry,G.A., Northup,W.D. and Shapiro,J.F.,"Computational Experience with a Group Theoretic Integer Programming Algorithm", Math. Prog., 4 (1973) 171-192.

[11] Held,M. and Karp,R.M.,"The Traveling-Salesman Problem and Minimum Spanning Trees", Operations Research, 18 (1970) 1138-1162.

[12] Held,M. and Karp,R.M., "The Traveling-Salesman Problem and Minimum Spanning Trees: Part II", Math. Prog., 1 (1971) 6-25.

Yoshitsugu YAMAMOTO : Department of Information Sciences, Tokyo Institute of Technology, Oh-okayama, Meguro-ku, Tokyo 152, Japan. 
有界整数計画問題に対する双対 ギャップのない群論的双対問題

東京工業大学 山 本 芳 嗣

本論文では, 变数に上界制約のある整数計画問題に対して双対ギャップを持たない群論的双対問題 を提案する。この双対問題の最適解は容易に求めることがでを，てれによって与えられた有界整数計 画問題が 1 つ群最適化問題を解くことに㷌着されるととが示される。 